\title{
Activity-Dependent Development of Synaptic Varicosities at Crayfish Motor Terminals
}

\author{
G. A. Lnenicka, S. J. Hong, M. Combatti, and S. LePage \\ Neurobiology Research Center, Department of Biological Sciences, State University of New York, Albany, New York \\ 12222
}

Tonically and phasically active crayfish motor terminals have well-characterized differences in synaptic physiology. During repetitive activation, the tonic terminals show facilitation and no depression, while the phasic terminals show dramatic synaptic fatigue. It has been proposed that this greater capacity for transmitter release from tonic terminals may be largely due to the presence of large synaptic varicosities along tonic terminals that contain large mitochondria, synapses, and numerous synaptic vesicles. In addition, a recent study indicates that in vivo tonic stimulation of a phasic terminal in young animals increases the fatigue resistance of the neuromuscular synapses and increases the number of synaptic varicosities, as well as the size of mitochondria and synapses. Because these previous morphological studies of crustacean motor terminals were performed using transmission electron microscopy, only short lengths of terminal were observed, and changes in synaptic varicosity frequency and size could not be thoroughly examined. In order to examine the synaptic varicosities along the terminal, motor terminals were injected with HRP, and the morphology of contrast-enhanced light microscopic images was examined. We report here that tonic terminals have much larger and more numerous synaptic varicosities than phasic terminals. In vivo stimulation of a phasic motoneuron results in an increase in the frequency of synaptic varicositles. This represents an increase in the total number of varicosities because terminal length appears to remain constant. These synaptic varicosities appear to form along preexisting terminals and persist for days after the final in vivo stimulation. The results indicate that the greater transmitter-releasing capabilities of tonic terminals compared to phasic terminals are due to their larger and more frequent synaptic varicosities. In addition, the development of these synaptic varicosities is activity dependent.

Activity-induced changes in synaptic physiology occurring during development, as well as during learning, may be largely dependent on changes in synaptic morphology. Evidence has indicated that changes in synaptic morphology result from altered experience during development (Greenough et al., 1985;

\footnotetext{
Received July 10, 1990; revised Nov. 13, 1990; accepted Nov. 19, 1990.

This work was supported by NSF Grant BNS-8720135 awarded to G.A.L. We would like to thank Michelle Gulker and Christopher Case for technical assistance, Ryland Loos for assisting with the illustrations, and Drs. John Schmidt and Suzannah Tieman for critical review of the manuscript.

Correspondence should be addressed to $G$. A. Lnenicka at the above address. Copyright (C) 1991 Society for Neuroscience 0270-6474/91/111040-09\$03.00/0
}

Tieman, 1985; Turner and Greenough, 1985; Sirevaag and Greenough, 1987) as well as underlie learning in the adult (Bailey and Chen, 1983, 1988; Greenough and Bailey, 1988). At the crustacean neuromuscular junction, the physiological differentiation of tonically and phasically active neuromuscular synapses appears to be influenced by electrical activity (Lnenicka and Atwood, 1985b). Phasic terminals release large amounts of transmitter initially but fatigue rapidly and thus have a reduced capacity for transmitter release compared to their fatigue-resistant, tonic counterparts. Tonic in vivo stimulation of a phasic motoneuron results in a decrease in initial transmitter release and increased fatigue resistance of its neuromuscular synapses (Lnenicka and Atwood, 1985a,b, 1989), transforming its physiology into one more similar to a tonic motoneuron.

These physiological differences between phasic and tonic motor terminals may be largely due to ultrastructural differences. Tonic motor terminals appear to contain large synaptic varicosities with large synapses, and a high mitochondrial and synaptic vesicle content, as indicated by studies in crayfish (Lnenicka et al., 1986), lobster (Hill and Govind, 1981), crab (Atwood and Johnston, 1968; Atwood and Jahromi, 1978), locust (Titmus, 1981), and moth (Rheuben, 1984). In addition, serialsection electron microscopy has indicated that tonic in vivo stimulation of a phasic motoneuron produces synaptic varicosities containing enlarged mitochondria and synapses (Lnenicka et al., 1986). These changes transform the synaptic terminal phenotype to one more similar to a tonic motoneuron and may be responsible for the observed physiological transformation, in particular, the increased fatigue resistance.

Because the prevalence of synaptic varicosities may be an important morphological feature differentiating phasic and tonic terminals and may be involved in the activity-dependent transformations of terminal type, we wished to examine the synaptic varicosities along tonic, phasic, and conditioned phasic terminals. In the previous study comparing terminal morphology, thin-section electron microscopy was used, by which terminal shape could not be extensively examined (Lnenicka et al., 1986), and therefore we wished to examine these changes with the light microscope. Phasic and tonic terminal morphology has not been previously compared using light microscopy, largely because of the lack of specific markers for the terminals. Utilizing techniques that allow the motor axons to be penetrated near the motor terminals (Wojtowicz and Atwood, 1984), the terminals were injected with HRP, and tonic and phasic terminals, as well as conditioned phasic terminals, were analyzed using videomicroscopy and digital contrast enhancement. The results demonstrate that the tonic terminals have a larger size and frequency of synaptic varicosities than do phasic terminals. The development of these synaptic varicosities appears to be activity de- 
pendent, because there is a 3 -fold increase in the frequency of varicosities in phasic terminals after tonic stimulation. These synaptic varicosities apparently form along previously existing terminals and, once established, persist for a number of days. These results demonstrate a strong correlation between the transmitter-releasing properties of the terminals and the number and size of synaptic varicosities, as well as the role of activity in the development of synaptic varicosities.

A preliminary report on these findings has previously appeared (Lnenicka and LePage, 1988).

\section{Materials and Methods}

In vivo conditioning of the phasic synaptic terminals. The implantation of electrodes for long-term stimulation of the phasic axon to the claw closer muscle was performed as previously described (Lnenicka and Atwood, 1985b). The phasic axon was stimulated at $10 \mathrm{~Hz}$ for $1 \mathrm{sec}$ every $2 \mathrm{sec}$ for $2 \mathrm{hr} / \mathrm{d}$. The phasic axon in 1 claw was stimulated for an average of $10.9 \mathrm{~d}$ (range, $7-14 \mathrm{~d}$ ) in the 9 conditioned crayfish examined in this study. Claws were examined at various intervals after the final conditioning period. One to $6 \mathrm{~d}$ after the final stimulation period, both claws were removed, and HRP was injected into both the control and the conditioned phasic axons. Only juvenile crayfish (Procambarus clarkil) with symmetric claws $1.0-1.2 \mathrm{~cm}$ in length and carapace lengths of $2.1-$ $2.6 \mathrm{~cm}$ were used in this study. All experiments were performed on animals collected in Louisiana (Atchafalaya Biological Supply Company, Raceland, LA) during the winter and spring.

Dye injection. The opener muscle was removed to expose the dorsal surface of the closer muscle. In order to penetrate the axon, the nerve bundle containing the tonically active slow closer excitor and the phasically active fast closer excitor was carefully lifted with a hook (see Fig. 1). Using optic fiber lighting, the axons could normally be visualized and penetrated with a microelectrode advanced with a Burleigh Inchworm (Burleigh Instruments, Fishers, NY). The axons was identified by stimulating the closer nerve with a suction electrode while recording EPSPs from the muscle fibers and determining if the intracellularly recorded action potential was coincident with the phasic or tonic EPSP. Pressure injection of HRP was performed by combining and modifying techniques previously employed by Muller and McMahan (1976), Watson and Burrows (1981), and Bailey et al. (1979). The electrode tips were filled with $15 \%$ HRP (Sigma VI) in $0.1 \mathrm{~m} \mathrm{KCl}$. The barrel of the electrode was filled with $0.1 \mathrm{M} \mathrm{KCl}$. Pressure was applied continuously for $30 \mathrm{~min}$ to $1 \mathrm{hr}$. Electrode resistance, typically 80-100 M , was monitored to determine if the electrode was blocking, and the physiological condition of the preparation was monitored by observing the membrane potential and the amplitude and duration of the action potential. After injection, the tissue was incubated at $15^{\circ} \mathrm{C}$ for $3-4 \mathrm{hr}$ in order to allow the fine processes to be filled with HRP. For this study, a total of 26 axons were successfully penetrated and filled with HRP, including 9 conditioned phasic axons, 4 contralateral control phasic axons, 7 phasic axons from untreated animals, and 6 tonic axons from untreated animals.

Tissue processing. The HRP-injected motor terminals were processed according to the technique of Itoh et al. (1979), which uses cobalt intensification (Adams, 1977) along with the coupled oxidation reaction (Lundquist and Josefsson, 1971). This technique provided good labeling and preservation of ultrastructure in a previous study of these terminals (Lnenicka et al., 1986) and has been shown to provide good visualization of fine processes in the nervous system of insects (Watson and Burrows, 1981). After glutaraldehyde fixation, the tissue was washed in $0.1 \mathrm{M}$ phosphate buffer $(\mathrm{pH}, 7.4)$ with $5 \%$ sucrose followed by a wash with $0.2 \mathrm{M}$ Tris buffer ( $\mathrm{pH}, 7.4$ ). The tissue was soaked in $0.5 \%$ cobalt chloride in Tris buffer for $10 \mathrm{~min}$ (Adams, 1977) and then washed with phosphate buffer. The tissue was then incubated for $1-2 \mathrm{hr}$ at $37^{\circ} \mathrm{C}$ in $20 \mathrm{ml} 0.05$ phosphate buffer containing $10 \mathrm{mg}$ diaminobenzidine, $8 \mathrm{mg}$ ammonium chloride, $40 \mathrm{mg} \beta$-D-glucose, and $10 \mathrm{U}$ glucose oxidase (Sigma V). The tissue was observed during incubation, and when background staining began to increase, the reaction was stopped by rinsing with phosphate buffer. The tissue was then dehydrated, and the surface fibers were removed in a single slab of about $0.5 \mathrm{~mm}$ thickness. After clearing in xylene, the tissue was mounted in permount on a slide.

Image processing and morphological measurements. The terminals were viewed with a Dage 65 (Dage/MTI Inc., Michigan City. IN) camera attached to an Olympus BH-2 microscope using bright-field illumination. The video signal was processed with an Intellect 100 Image Processor (Quantel Ltd., Kenley, Surrey, UK) and displayed on an Electrohome monitor (Electrohome Ltd., Kitchener, Ontario, CAN). Using this video system, previously described by Tieman et al. (1986), the image was contrast enhanced, and the background noise was subtracted. Microscopy was performed using either an Olympus $100 \times$ objective (NA, 1.25) or $60 \times$ objective (NA, 1.40). Measurements of terminal morphology were made from the monitor screen using a mouse-controlled cursor.

Measurements of terminal morphology were performed only on distal terminal branches (i.e., those that underwent no further branching). Beginning at the distal end of randomly selected branches, $10-\mu \mathrm{m}$ lengths were analyzed for the number of varicosities, the length and apparent maximum diameter of varicosities, and the maximum and minimum apparent diameters of the terminal branch. Two or 3 sequential $10-\mu \mathrm{m}$ lengths were measured per distal terminal branch. In several animals, the number of varicosities was measured for the entire terminal branch, and the branch length was determined. All measurements were performed blind, and values are expressed as mean \pm standard error, where $n$ refers to the number of claws. Comparisons for significance were performed with a 2-tailed $t$ test using mean values from individual claws.

Comparison of synaptic terminal morphology revealed by IIRP and Lucifer yellow. In 2 cases, Lucifer yellow (Stewart, 1981) was pressure injected into the tonic axon, and terminal morphology was examined after fixation in formaldehyde. This technique gave similar values for varicosity frequency and size as the HRP injections. However, it was generally found that the HRP-filled terminals were preferred because the Lucifer yellow fills faded quickly during examination with high-NA objectives and did not allow the shape of fine processes to be as easily resolved. Thus, all measurements of terminal shape were performed on HRP-filled terminals except for 2 measurements performed on tonic terminals filled with Lucifer yellow.

\section{Results}

The crayfish claw closer muscle is innervated by the phasically active fast closer excitor and the tonically active slow closer excitor (Wiersma, 1961). Physiological measurements indicate that the muscle fibers on the dorsal surface of the closer muscle are innervated by both excitors.

Morphology of phasic and tonic synaptic terminals. As the phasic and tonic axons enter the proximal region of the closer muscle, they branch in parallel, sending one branch deep into the muscle and a second branch to the dorsal surface of the muscle. The synaptic terminal arbors originating from this superficial branch were examined in this study. The superficial axon branch typically ran down the center of the muscle and formed a Y-branch (Fig. 1). HRP injection into the superficial branch just proximal to the $\mathrm{Y}$ resulted in the filling of only the terminal arbors originating from the superficial branch. In a few instances where both the tonic and the phasic axons were injected with HRP, the 2 axons were observed to branch in parallel.

Observations of the phasic and tonic terminal arbors at low power revealed obvious differences in shape (Fig. 2). The tonic terminals were varicose, most terminals having a series of welldifferentiated synaptic varicosities and bottlenecks. In contrast, the phasic motor terminals were generally thinner in diameter and lacked the large synaptic varicosities found in the tonic terminals.

Morphology of conditioned synaptic terminals. The rolc of impulse activity in the differentiation of terminal shape for the phasic and tonic axons was examined by stimulating the phasic motoneuron in vivo (see Materials and Methods). The phasic axon was conditioned for 1-2 weeks, a period of conditioning previously shown to be sufficient to transform the physiology of the synaptic terminals to a more tonic type (Lnenicka and 


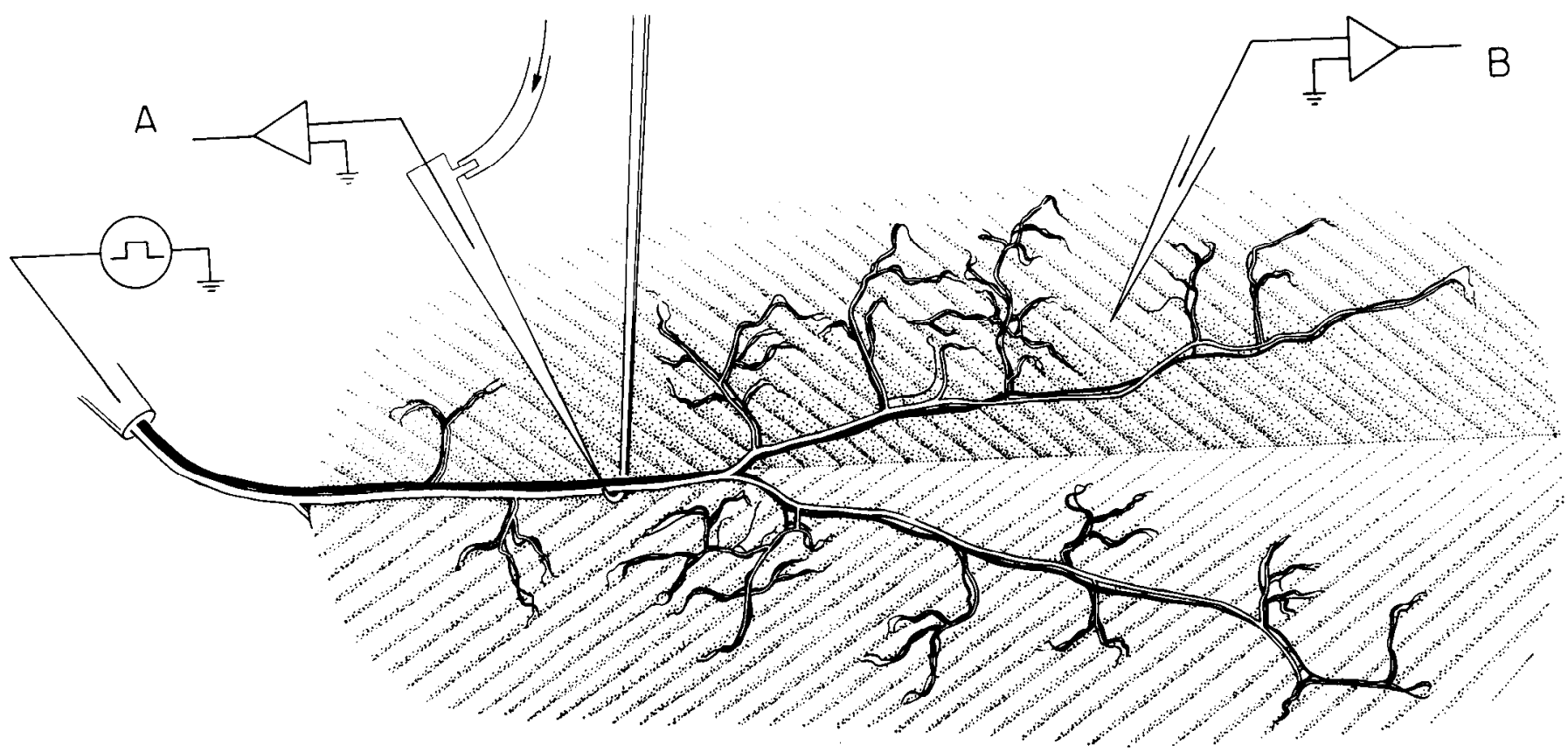

Figure 1. Schematic diagram showing the preparation used for pressure injection into the axon of the phasically active fast closer excitor or the tonically active slow closer excitor motor axons innervating the crayfish closer muscle. The dorsal surface of the closer muscle (shown here) is innervated by a superficial branch of the nerve bundle containing the phasic and tonic motor axons. The phasic and tonic motor axons typically run along the midline of the muscle until they form a Y-branch. Branches arise in parallel from the 2 axons, forming terminal arbors. Note that the full extent of the terminal arbors is not shown in this diagram because only the largest terminal branches are included, and, in addition, many of the terminals travel beneath the surface of the muscle. The axons were routinely penetrated with a microelectrode for pressure injection by supporting the bundle with a hook. The axons were physiologically identified before injection by recording from the axon during stimulation with a suction electrode $(A)$ while simultaneously recording the EPSP in the muscle fibers ( $B$; see Materials and Methods). The total length of the muscle is approximately $4 \mathrm{~mm}$, though individual structures are not necessarily drawn to scale.

Figure 2. Representative camera lucida drawings of tonic, phasic, and conditioned terminal arbors after injection of HRP. Differences in the shape of the phasic and tonic terminals are apparent, with the tonic terminals having many more synaptic varicosities. The conditioned terminal arbor is from an animal in which the phasic axon was stimulated for 1 week and HRP was injected $3 \mathrm{~d}$ after the final conditioning period. There is an obvious increase in the number of synaptic varicosities as a result of this conditioning regime. The proximal ends of the arbors, indicated with asterisks, are connected to primary or secondary branches arising from the axon, as shown in Figurc 1. Typical distal terminal branches subsequently examined at higher magnification are marked with arrows. Approximate muscle fiber borders are represented schematically.

\section{PHASIC}

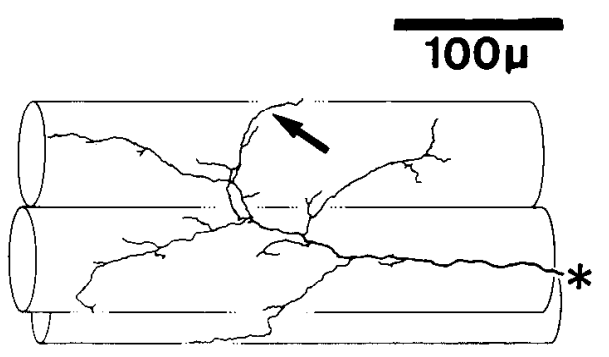

\section{CONDITIONED}

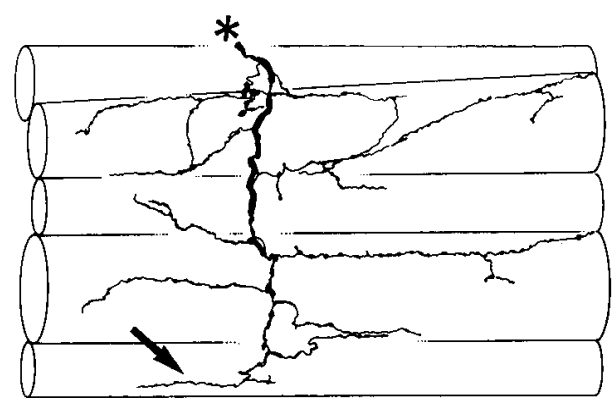

\section{TONIC}

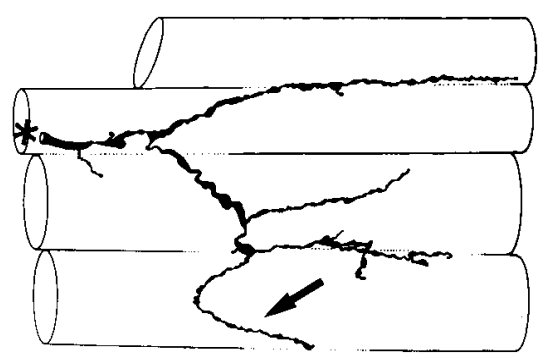




\section{TONIC}

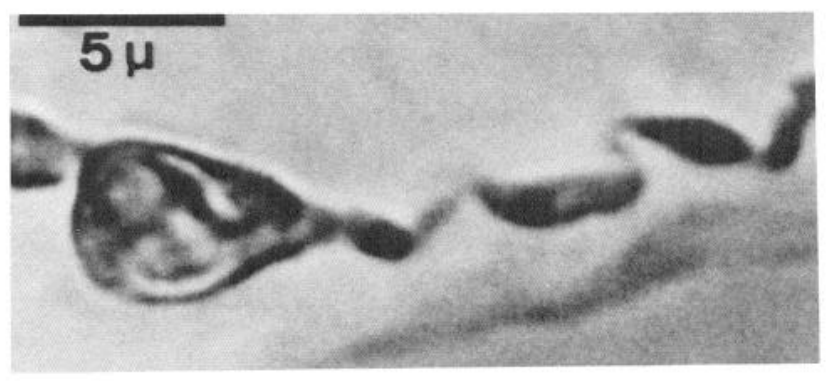

\section{PHASIC}

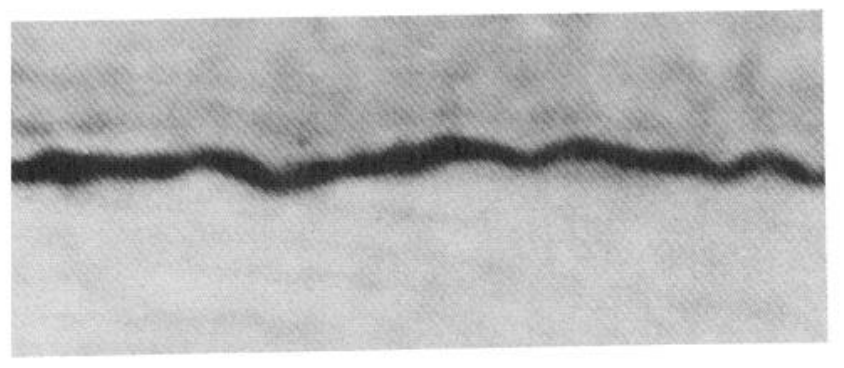

\section{CONDITIONED}

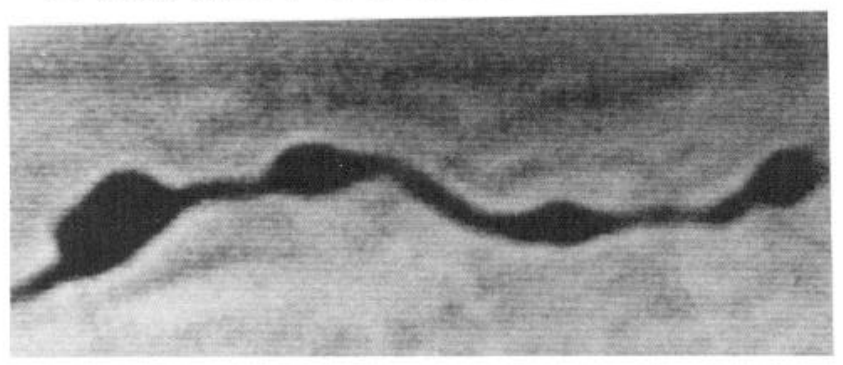

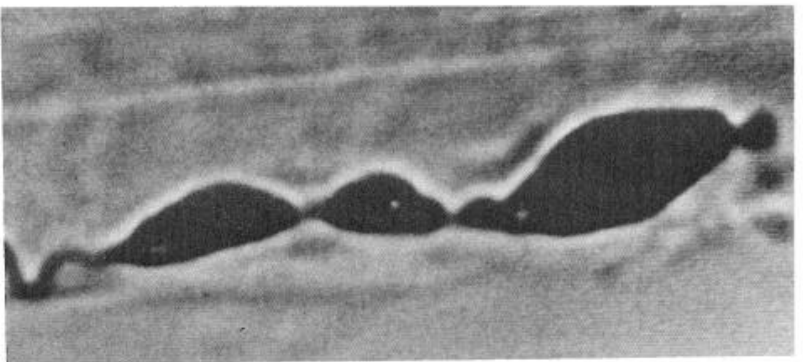
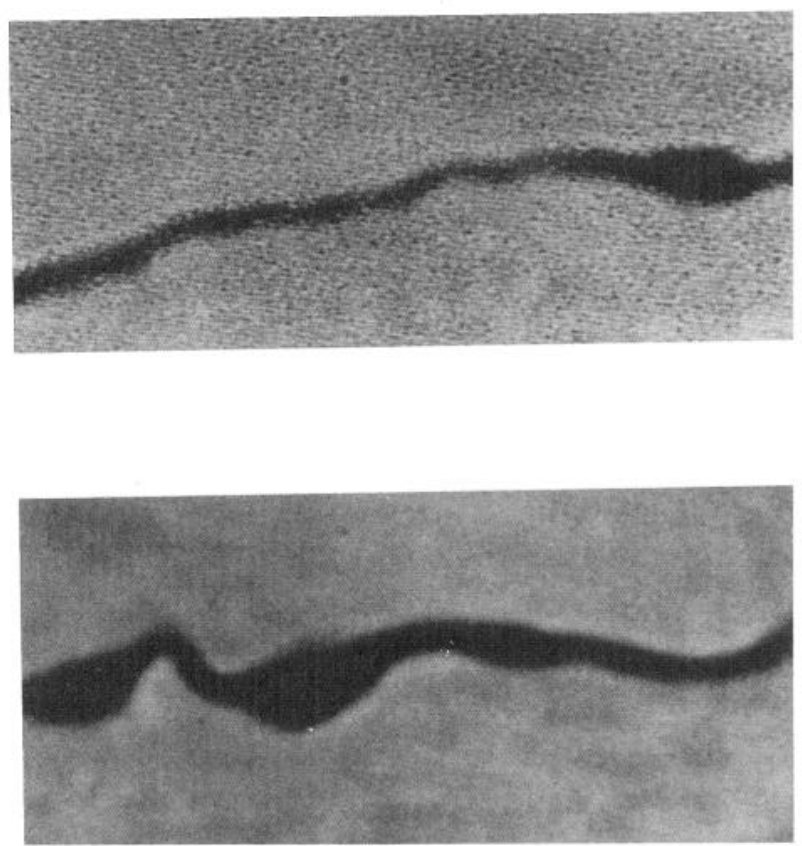

Figure 3. Segments of distal terminal branches visualized at higher magnification. Phasic terminal branches were typically slender and uniform in diameter, containing few or no synaptic varicosities. Tonic terminal branches contained many synaptic varicosities, some of which were large and separated by more slender bottlenecks. Conditioned phasic terminal branches contained numerous synaptic varicosities compared to the control phasic terminals. In general, the varicosities of conditioned terminals were not as large as those found along the tonic terminals. Differences in the density of varicosities are probably due to differences in the amount of HRP injected into the axon. Terminals were observed with an Olympus $100 \times 1.25$-NA lens, contrast enhanced, and photographed from the monitor.

Atwood, 1985a,b). Conditioning was performed on the phasic motoneuron in one of the paired claws, and the contralateral claw was used as a control. Conditioning of the phasic terminals resulted in an increase in the number of synaptic varicosities seen along the terminal (Fig. 2).

Quantification of the morphology of tonic, phasic, and conditioned synaptic terminals. In order to examine these differences in synaptic terminal morphology more closely, terminals were examined at higher power using videomicroscopy and contrast enhancement. The morphology of the phasic, tonic, and conditioned synaptic terminals was compared by examining distal terminal branches (i.e., those that underwent no further branching), which allowed us to sample similar regions of the terminal arbors and increased the probability that we were always examining synapse-bearing terminals. Comparing the morphology of the phasic and tonic distal terminal branches revealed dramatic differences in terminal shape and size (Fig. 3). The major difference was the greater number and size of varicosities along the tonic terminal branches. Conditioned terminal branches were intermediate in appearance; they were more varicose than phasic terminal branches but less so than tonic terminal branches (Fig. 3).

These differences in morphology were quantified for the distal terminal branches. The following measurements were performed: the frequency of varicosities, the length and apparent diameter of varicosities, and the maximum/minimum apparent terminal diameter per $10-\mu \mathrm{m}$ length of terminal branch.

The number of synaptic varicosities per $10-\mu \mathrm{m}$ of terminal for tonic, phasic, and conditioned phasic motor terminals is shown in Figure 4. The frequency of synaptic varicosities for tonic terminals $(1.93 \pm 0.14 ; n=8)$ was significantly greater than for phasic terminals $(0.39 \pm 0.06 ; n=11 ; p<0.001)$. The 


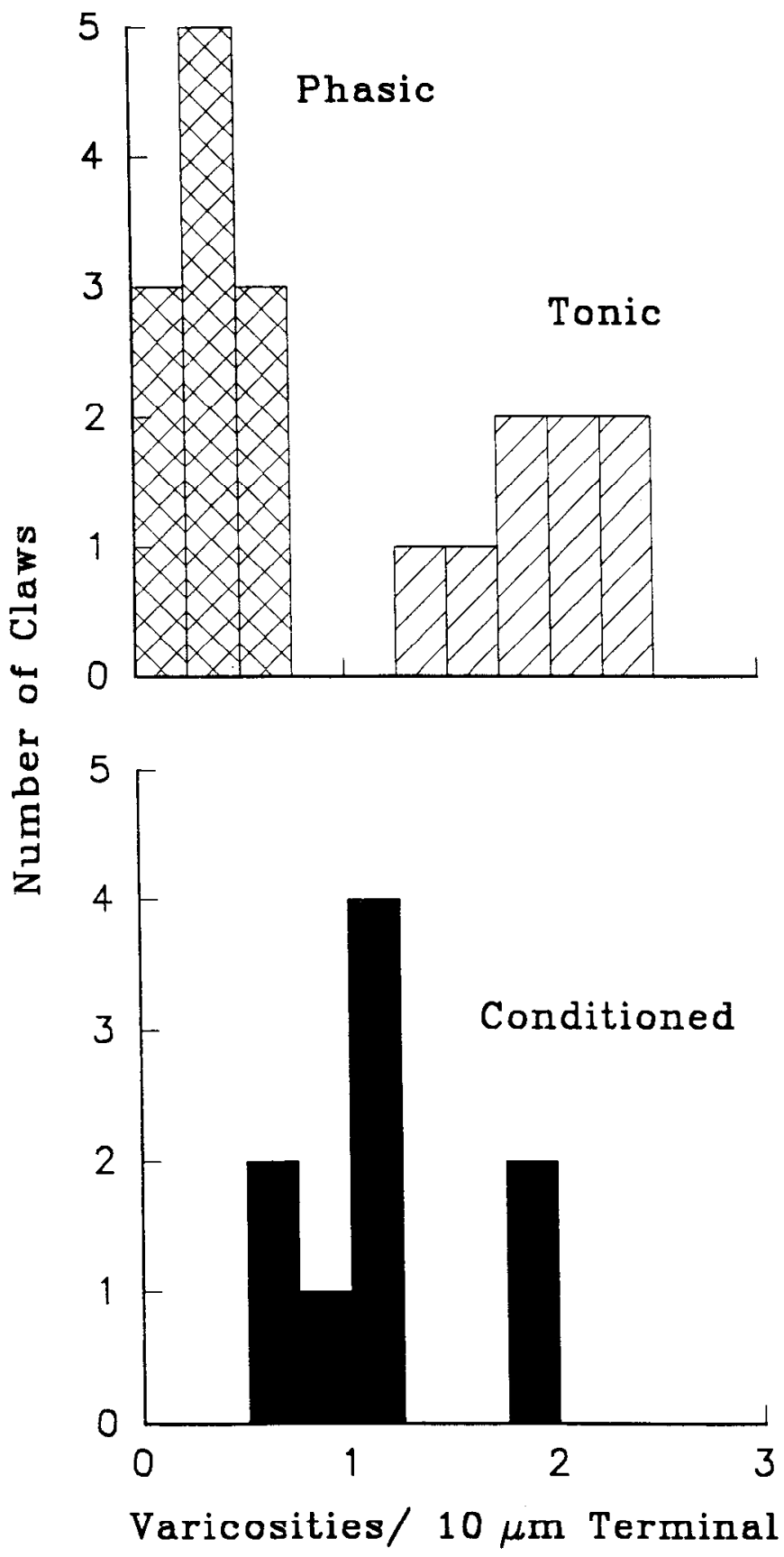

Figure 4. Histogram of synaptic varicosity frequency for the distal terminal branches of control phasic, tonic, and conditioned phasic motor axons. For each claw, either the control phasic, tonic, or conditioned phasic axon was injected with HRP, and measurements were performed as previously described (see Materials and Methods). An approximately $400-\mu \mathrm{m}$ length of terminal was analyzed per claw, and the mean value for each claw was determined. The frequency of varicosities was significantly greater for the tonic terminals compared to the control phasic terminals, while conditioning resulted in a significant increase in the frequency of varicosities in the phasic terminals.

phasic terminal value includes control claws, which were contralateral to the conditioned claw, as well as normal claws from unstimulated animals. Because frequency values for the control claws $(0.34 \pm 0.14 ; n=4)$ were similar to normal claws $(0.42$ $\pm 0.06 ; n=7)$, they were combined. For the remainder of the study, values for phasic terminals will include measurements from normal claws and contralateral control claws.
As a result of conditioning, there was an increase in the frequency of synaptic varicosities along the phasic terminal branches (Fig. 4). The conditioned phasic terminals had $1.13 \perp 0.15$ varicosities per $10 \mu \mathrm{m}$ of terminal $(n=9)$, which was significantly greater than for control phasic terminals $(p<0.001)$. Thus, tonic conditioning resulted in approximately a 3-fold increase in synaptic varicosity frequency, making the phasic terminals more similar to tonic terminals. However, the conditioned terminals still had significantly fewer varicosities than tonic terminals $(p<0.002)$.

In order to confirm the changes in terminal shape indicated by the increase in synaptic varicosity number, the maximum/ minimum ratio per $10-\mu \mathrm{m}$ terminal branch segment was compared for the control and conditioned phasic terminals. This ratio was determined from measurements of apparent minimum and maximum terminal diameters for a $10-\mu \mathrm{m}$ length of terminal. Consistent with the increase in varicosity frequency, the conditioned terminals also showed a significantly larger max/ min ratio $(4.21 \pm 0.38 ; n=9)$ than did the control phasic terminals $(2.03 \pm 0.10 ; n=11 ; p<0.001)$.

Finally, a comparison was made of the size of synaptic varicosities in tonic, phasic, and conditioned phasic terminal branches. The length $(L)$ and apparent maximum diameter $(D)$ of synaptic varicosities in tonic terminals $(D=1.9 \pm 0.1 \mu \mathrm{m}$; $L=3.1 \pm 0.1 \mu \mathrm{m})$ are significantly greater than in phasic terminals $(D=0.9 \pm 0.1 \mu \mathrm{m} ; L=1.8 \pm 0.1 \mu \mathrm{m} ; p<0.001)$. Varicosities seen along conditioned terminals $(D=1.0 \pm 0.13$ $\mu \mathrm{m} ; L=1.9 \pm 0.1 \mu \mathrm{m}$ ) were similar in size to those found along phasic terminals, but were more frequent. This can be seen quite clearly in Figure 3.

Terminal length. In order to examine whether conditioning influenced terminal length and number, the length and number of terminal branches were measured from camera lucida drawings of terminal arbors. For each claw, the length of 25-30 distal tcrminal branches was mcasured. The length of the conditioned phasic terminal branches $(61.2 \pm 6.4 \mu \mathrm{m} ; n=9)$ was not significantly different from the control phasic terminal branches $(60.0 \pm 11.8 \mu \mathrm{m} ; n=10 ; p>0.10)$. The total number of branches per terminal arbor was not significantly different comparing control $(10.1 \pm 1.4 ; n=11)$ and conditioned $(9.1 \pm 1.1$; $n=9 ; p>0.10$ ) phasic axons. Similarly, the number of distal terminal branches per conditioned lerminal arbor $(5.1 \pm 0.6 ; n$ $=9$ ) was not significantly different from control $(5.6 \pm 0.8 ; n$ $=11) ; p>0.10)$. Thus, there is no evidence that this conditioning regime influences terminal length. The increase in varicosity frequency produced by conditioning represents an increase in the total number of synaptic varicosities per terminal.

Do varicosities form along preexisting or newly formed terminals? In order to address this question, we examined whether synaptic varicosities form along all terminal branches uniformly or only along sclective terminal regions. To that end, the varicosity frequency was measured along the total length of individual terminals in some of the animals, rather than just the distal ends as in the previous measurements. If synaptic varicosities occur only on newly formed terminals, they might be expected at the ends of growing terminal branches. In this case, a lower value for varicosity frequency would be obtained from measurements of whole terminal branches compared to end regions. If whole terminal branches were newly formed, a bimodal distribution of varicosity frequencies might be expected when comparing individual terminal branches. The varicosities appeared to be evenly distributed along all the terminal branch- 

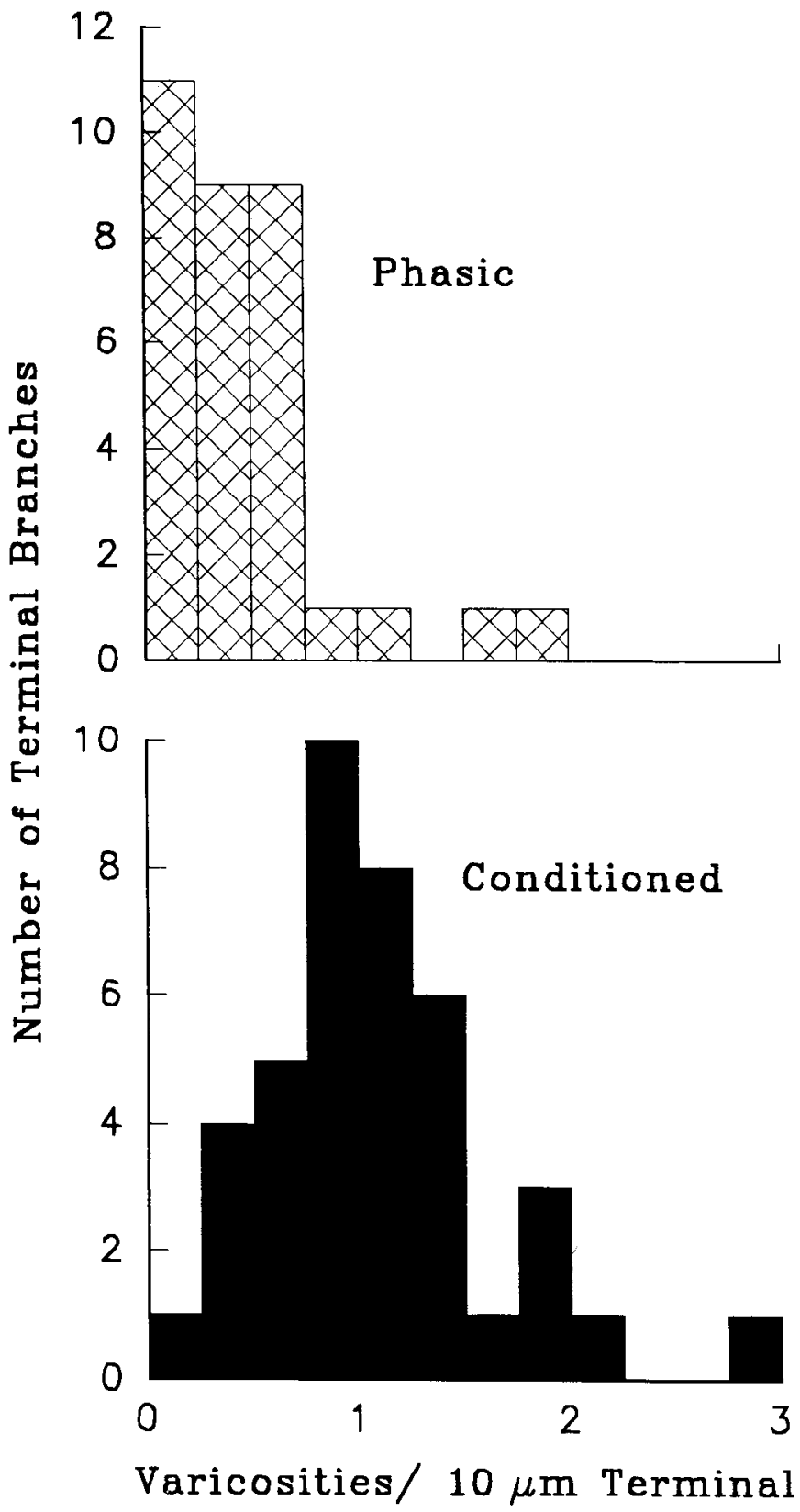

Figure 5. Histogram of synaptic varicosity frequency for entire distal terminal branches from control phasic and conditioned phasic motor axons. In order to determine if the varicosities form either uniformly along all the terminals or only along a sclcct subpopulation of terminals, the distribution of synaptic varicosity frequency for individual terminals was examined. The number of synaptic varicosities was measured along the entire terminal length, and the mean frequency was determined. Varicosity frequency was determined for 40 conditioned distal terminal branches from 9 claws and 33 control distal terminal branches from 7 claws. The increase in synaptic varicosity frequency appears to occur uniformly in all terminals because the conditioned terminal branches form a normal distribution. These results support the activity-induced formation of synaptic varicosities along preexisting synaptic terminals.

es. This was verified by measurements that showed that the frequency values obtained from the whole terminal branches of the conditioned phasic axon $(1.02 \pm 0.1 ; n=9)$ were very similar to those previously reported for the terminal branch end regions of the conditioned phasic axon $(1.13 \pm 0.15 ; n=9)$. In addition, the varicosities do not appear to occur exclusively

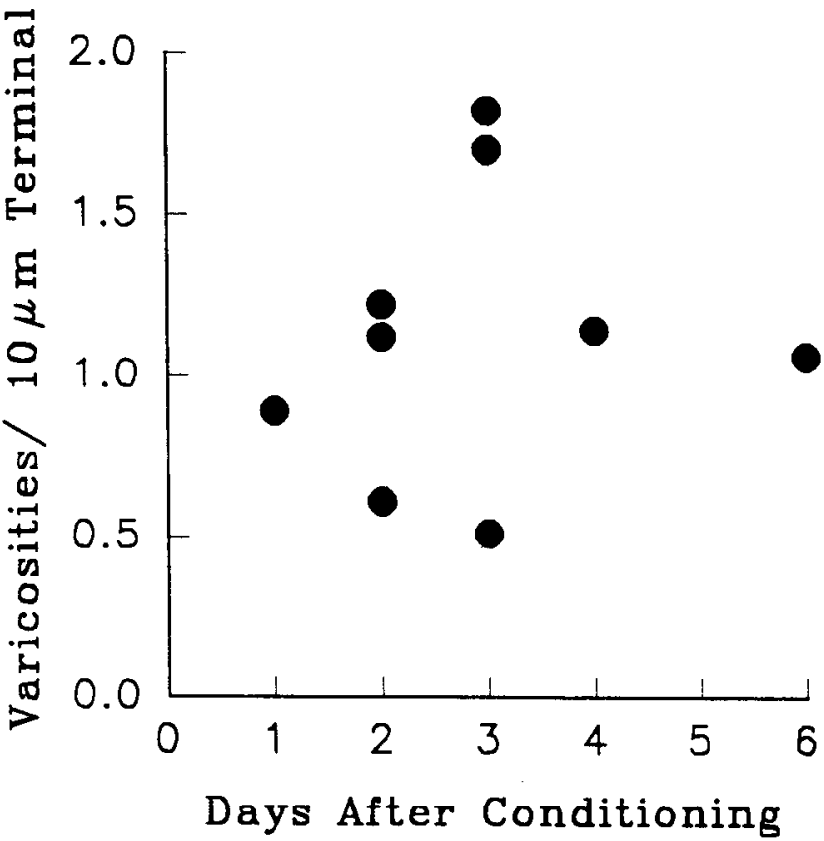

Figure 6. Synaptic varicosity frequency measurements made at various intervals after the final in vivo conditioning period. The conditioned claws were removed $1-6 \mathrm{~d}$ after the final conditioning period, and HRP was injected into the conditioncd phasic axon. The varicosity frequency values obtained indicate that the morphological change persists over a period of days because there is no trend for a decrease in varicosity frequency.

along a subpopulation of newly formed terminal branches because there is no evidence of a bimodal distribution of terminal branch varicosity frequencies (Fig. 5).

Persistence of morphological changes. Is this morphological change long lasting or transient? The previously reported physiological changes probably persist for weeks (Lnenicka and Atwood, $1985 \mathrm{a}, \mathrm{b}$ ). In order to examine the persistence of the activity-induced synaptic varicosities, measurements were made at various intervals after the final conditioning period. For intervals up to $6 \mathrm{~d}$, the frequency of synaptic varicosities appears to remain stable (Fig. 6). Values for days 3-6 (1.26 $\pm 0.25 ; n$ $=5)$ were not less than values for days 1 and $2(0.96 \pm 0.14$; $n=4)$ and were significantly greater than the control phasic terminals $(0.39 \pm 0.06 ; n=11 ; p<0.001)$.

\section{Discussion}

Morphology of phasic, tonic, and conditioned phasic motor terminals. This study demonstrates that one of the major morphological differences between phasic and tonic invertebrate motor terminals is the shape of the synaptic terminals. Tonic terminals are organized into varicosities separated by thin bottleneck regions, while phasic terminals are thin and uniform in diameter with only occasional varicosities. In vivo stimulation of the phasic motor axon results in a transformation of the terminal shape towards a more tonic type: there is an increase in the number of synaptic varicosities per length of terminal.

This light microscopic investigation supports the findings of an earlier electron microscopic study. In the previous study, in which a total of $202 \mu \mathrm{m}$ of terminal was examined in 4 claws, the frequency of varicosities per $10-\mu \mathrm{m}$ length of terminal for phasic, tonic, and conditioned phasic terminals was estimated to be $0.4,1.4$, and 1.3, respectively (Lnenicka et al., 1986). In 
the present study, in which a total of $10,925 \mu \mathrm{m}$ of terminal was measured in 28 claws, the frequency values for phasic, tonic, and conditioned phasic terminals were $0.4,1.9$, and 1.1 , respectively. Given the small sample size of the earlier study, the results are remarkably similar.

This activity-induced increase in synaptic varicosity frequency represents an increase in the total number of synaptic varicosities per terminal. Conditioning did not alter the length or number of distal terminal branches, and therefore the number of varicosities per terminal increased approximately 3 -fold. Thus, individual muscle fibers apparently receive 3 -fold more synaptic varicosities after conditioning.

The previous electron microscopic study of these terminals indicated that the varicosities contain a large synaptic contact area, large mitochondria, and numerous synaptic vesicles (Lnenicka et al., 1986). Are the varicosities viewed with the light microscope the same as those previously examined with the electron microscope? As previously mentioned, they appear to occur at a similar frequency for both studies. In addition, they are similar in size: the apparent maximum diameters of the varicosities in this study are 1.9 and $1.0 \mu \mathrm{m}$ for tonic and conditioned terminals, respectively; the varicosities viewed with the electron microscope were 1.7 and $1.2 \mu \mathrm{m}$, respectively. Thus, it appears that the varicosities examined in this study are likely the synaptic varicosities described previously.

Correlation of synaptic physiology and morphology. Previous physiological measurements indicate that phasic terminals release more transmitter during initial or low-frequency stimulation than do tonic terminals (Lnenicka, 1988). However, in this case, low-frequency stimulation is not a good measure of "synaptic strength," because higher-frequency stimulation for prolonged periods shows that the tonic terminals are capable of releasing much more transmitter than are phasic terminals. Indeed, given the normally higher activity levels of the tonic motoneurons, its synapses release more transmitter under physiological conditions (Lnenicka, 1988). The greater transmitterreleasing capability of the tonic terminals is correlated with a more robust morphology and larger and more frequent synaptic varicosities compared to phasic terminals. The larger population of synaptic vesicles and large mitochondria found in the tonic synaptic varicosities may be responsible for their ability to release large amounts of transmitter for prolonged periods. After conditioning of the phasic terminals, one of the major changes in physiology is an increase in the fatigue resistance of the tcrminals. The increased number of synaptic varicosities resulting from conditioning may be responsible for this increased fatigue resistance. This is further supported by the findings that both the morphological transformation reported here and the physiological transformation (Lnenicka and Atwood, 1985b) result in properties intermediate between the phasic and tonic terminals. Recent evidence lends additional support to this correlation between synaptic varicosity frequency and fatigue resistance. Animals collected during the summer, when they are presumably more active, have more fatigue-resistant phasic axon synaptic terminals and a greater frequency of synaptic varicosities compared to winter animals (Lnenicka and Zhao, 1990).

While the formation of synaptic varicosities may be responsible for the increased fatigue resistance produced by conditioning, what is responsible for the decrease in initial transmitter release? Thus far, there arc no observed morphological changes that could account for this physiological change. One possibility as yet unexamined is that there are changes in the number or organization of calcium channels. The organization of the large intramembranous particles thought to be calcium channels found at the active zones of a variety of animals, including crustaceans (Pearce et al., 1986), appears to be related to initial transmitter release (Walrond and Reese, 1985). Another possibility is that there are biochemical changes such as phosphorylation of channel or synaptic proteins underlying the reduction in initial transmitter release.

Activity-induced morphological changes. In this study, $7 \mathrm{~d}$ of conditioning was sufficient to induce the formation of synaptic varicosities. Currently, we do not know the minimum time required for this morphological change. It does appcar that for the rate of stimulation used in this study the maximum change occurs by $7 \mathrm{~d}$, because the results from 7 and $14 \mathrm{~d}$ of stimulation were similar. Recent evidence has shown that terminal varicosities can be induced within $24 \mathrm{hr}$ during learning in Aplysia (Bailey and Chen, 1989) and after the application of cAMP to Aplysia sensory neurons in organ culture (Nazif et al., 1989). The time course of the formation of these synaptic varicosities is presently not known.

The evidence indicates that the synaptic varicosities form along preexisting terminals. Synaptic varicosities form uniformly along the distal terminal branches and probably form along the entire terminal arbor (see Fig. 3). Thus, there is no evidence for their formation at sites of terminal growth. In fact, distal terminal branch length or number does not change as a result of conditioning, indicating that activity is not influencing terminal growth.

This change in terminal shape represents a dramatic change in the location of neuromuscular synapses. Varicosities in conditioned phasic terminals contained a concentration of synapses, while in control phasic terminals, synapses were evenly distributed along the terminal (Lnenicka et al., 1986). Thus, synapses go from a uniform distribution along the terminal to an uneven or "clumped" distribution. This requires the movement of synaptic membrane or the loss and reformation of synapses. Evidence from studies of the hippocampus indicates that synapses can form within minutes (Lee et al., 1980; Chang and Greenough, 1984).

Probably the simplest model for the formation of synaptic varicosities is that they are produced to accommodate the large mitochondria. There is evidence that swellings in axons (Friede and Martinez, 1970) and dendrites (Sasaki-Sherrington et al., 1984) are accompanied by the accumulation of intracellular organelles. The size of the mitochondria after conditioning may prohibit them from occupying the preexisting terminals in the absence of varicosities. It will be necessary to examine the sequence of morphological changes in order to test this hypothesis.

The mechanism through which activity produces these morphological changes is currently unknown. In particular, it is not known if impulse activity, transmitter release from the synaptic terminals, and/or postsynaptic activity are required to induce these changes. Some of the physiological changes can be produced by procedures that increase impulse activity exclusively in the central region of the motoneuron (Lnenicka and Atwood, 1989) or through subthreshold depolarization of the motoneuron cell body (Hong and Lnenicka, 1990). In addition, there is evidence that the physiological changes produced by conditioning require products from the cell body. Removing the cell body (Lnenicka and Atwood, 1985a) or blocking protein synthesis (Nguyen and Atwood, 1990) eliminates the physiological adaptation, including the increase in fatigue resistance. These re- 
sults suggest that the morphological changes reported here may require the involvement of the cell body.

Role of activity in synaptic terminal development. Is the differentiation of terminal morphology in phasic and tonic crustacean motoneurons solely due to their different activity levels? Evidence from this study demonstrates that the development of synaptic varicosities is definitely dependent on activity levels. However, the incomplete transformation of terminal type by imposed activity suggests that genetic predetermination, along with activity, may play a role in terminal development. We have not yet determined the extent to which activity regulates the development of these terminals. One might expect a greater effect of activity if either the activity levels were increased further or animals were stimulated earlier in development. Indeed, the physiological changes appear to be age dependent: old animals show less physiological change after conditioning than do young animals (Lnenicka and Atwood, 1985b).

Additional evidence that activity levels during development play a role in the differentiation of these motor terminals is provided by studies in which animals were examined at different seasons. Young animals collcctcd during the summer have more synaptic varicosities and greater fatigue resistance than do those collected during the winter (Lnenicka and Zhao, 1990). This may be due to the summer animals developing during a period of higher activity compared to winter animals.

Relationship to other synapses. Results consistent with those presented here have been reported for other neuromuscular synapses. Tonic moloneurons in mammals have more fatigue-resistant neuromuscular synapses than do phasic motoneurons (Gertler and Robbins, 1978). There is some evidence that these physiological differences are activity dependent (Robbins and Fischbach, 1971). Morphologically, mammalian tonic motor terminals are generally thicker, resulting in a greater surface area for tonic end plates than for phasic end plates (Dias, 1974; Waerhaug and Korneliussen, 1974; Fahim et al., 1984). Tonic stimulation of a mammalian fast nerve during ectopic neuromuscular junction formation results in a partial transformation to a slow junction type, suggesting that the development of motor terminal morphology is partially dependent upon electrical activity (Lomo and Waerhaug, 1985). Recent evidence in Drosophila indicates that the frequency of synaptic varicosities along motor terminals in the larva is greater if impulse activity is increased during development (Budnik et al., 1989).

Changes in the morphology of central synaptic terminals have been reported during learning and as a result of altered impulse activity during development. There is an increase in the number of synaptic varicosities along Aplysia sensory neuron terminals as a result of behavioral sensitization (Bailey and Chen, 1988). A reduction in impulse activity in the cat visual pathway during early postnatal development results in a reduction in the crosssectional area and mitochondria size at retinogeniculate synaptic terminals (Kalil et al., 1986) and geniculocortical synaptic terminals (Tieman, 1985). Interestingly, these morphological changes are accompanied by increased fatigability of responses in the visual cortex to visual stimuli (Wiesel and Hubel, 1965; Ganz et al., 1968). The findings reported here may be applicable to the development and plasticity of synaptic terminals in a variety of vertebrate and invertebrate species.

\section{References}

Adams JC (1977) Technical considerations on the use of horseradish peroxidase as a neuronal marker. Neuroscience 2:141-145.
Atwood HL, Jahromi SS (1978) Fast-axon synapses of a crab leg muscle. J Comp Physiol 124:237-247.

Atwood HL, Johnston HS (1968) Neuromuscular synapses of a crab motor axon. J Exp Zool 167:457-470.

Bailey $\mathbf{C H}$, Chen M (1983) Morphological basis of long-term habituation and sensitization in Aplysia. Science 220:91-93.

Bailey CH, Chen M (1988) Long-term memory in Aplysia modulates the total number of varicosities of single identified sensory neurons. Proc Natl Acad Sci USA 85:2373-2377.

Bailey CH, Chen M (1989) Onset of structural changes at identified sensory neuron synapses and the acquisition of long-term sensitization in Aplysia. Soc Neurosci Abstr 15:1285.

Bailey CH, Thompson EB, Castellucci VF, Kandel ER (1979) Ultrastructure of the synapses of sensory neurons that mediate the gillwithdrawal reflex in Aplysia. J Neurocytol 8:415-444.

Budnik V, Zhong Y, Wu C-F (1989) Projection of motor axons in hyperexcitable Drosophila mutants. Soc Neurosci Abstr 15:570.

Chang F-LF, Greenough WT (1984) Transient and enduring morphological correlates of synaptic activity and efficacy change in the rat hippocampus. Brain Res 309:35-46.

Dias PLR (1974) Surface area of motor end plates in fast and slow twitch muscles of the rabbit. J Anat 117:453-462.

Fahim MA, Holley JA, Robbins N (1984) Topographic comparison of neuromuscular junctions in mouse slow and fast twitch muscle. Neuroscience 13:227-235.

Friede RL, Martinez AJ (1970). Analysis of the process of sheath expansion in swollen nerve fibers. Brain Res 19:165-182.

Ganz L, Fitch M, Satterberg JA (1968) The selective effect of visual deprivation on receptive field shape determined neurophysiologically. Exp Neurol 22:614-637.

Gertler RA, Robbins N (1978) Differences in neuromuscular transmission in red and white muscle. Brain Res 142:160-164.

Greenough WT, Bailey CH (1988) The anatomy of a memory: convergence of results across a diversity of tests. Trends Neurosci 11: $142-147$.

Greenough WT, Hwang HMF, Gorman C (1985) Evidence for active synapse formation or altered postsynaptic metabolism in visual cortex of rats reared in complex environments. Proc Natl Acad Sci USA 82: 4549-4552.

Hill RJ, Govind CK (1981) Comparison of fast and slow synaptic terminals in lobster. Cell Tissue Res 221:303-310.

Hong SJ, Lnenicka GL (1990) Long-term regulation of transmitter release from crayfish motor terminals by depolarization of the motoneuron cell body. Soc Neurosci Abstr 16:1162.

Itoh K, Konishi A, Nomura S, Mizuno N, Nakamura Y, Sugimoto T (1979) Application of coupled oxidation reaction to electron microscopic demonstration of horseradish peroxidase: cobalt-glucose oxidase method. Brain Res 175:341-346.

Kalil RE, Dubin MW, Scott G, Stark LA (1986) Elimination of action potentials blocks the structural development of retinogeniculate synapses. Nature 323:156-158.

Lee KS, Schottler F, Oliver M, Lynch G (1980) Brief bursts of highfrequency stimulation produce two types of structural change in rat hippocampus. J Neurophysiol 44:247-258.

Lnenicka GA (1988) The role of neuronal activity in the long-term regulation of synaptic performance at the crayfish neuromuscular junction. In: Cellular mechanisms of conditioning and behavioral plasticity (Woody DC, Alkon DL, McGaugh JL, eds), pp 403-409. New York: Plenum.

Lnenicka GA, Atwood HL (1985a) Long-term facilitation and longterm adaptation at synapses of a crayfish phasic motoneuron. J Neurobiol 16:97-110.

Lnenicka GA, Atwood HL (1985b) Age-dependent long-term adaptation of crayfish phasic motor axon synapses to altered activity. $J$ Neurosci 5:459-467.

Lnenicka GA, Atwood HL (1989) Impulse activity of a crayfish motoncuron regulates its neuromuscular synaptic properties. J Neurophysiol 61:91-96.

Lnenicka GA, LePage S (1988) Activity-dependent differences in the numbers of synaptic varicosities at crayfish motor terminals revealed by light microscopy. Soc Neurosci Abstr 14:1208.

Lnenicka GA, Zhao Y (1990) Seasonal changes in the physiology and morphology of identified crayfish motor terminals. Soc Neurosci Abstr 16:1162.

Lnenicka GA, Atwood HL, Marin L (1986) Morphological transfor- 
mation of synaptic terminals of a phasic motoneuron by long-term tonic stimulation. J Neurosci 6:2252-2258.

Lomo T, Waerhaug $O$ (1985) Motor endplates in fast and slow muscles of the rat: what determines their differences? J Physiol (Lond) 80: 290-297.

Lundquist I, Josefsson J-O (1971) Sensitive method for determination of peroxidase activity in tissue by means of coupled oxidation reaction. Anal Biochem 41:567-577.

Muller KJ, McMahan UJ (1976) The shapes of sensory and motor neurons and the distribution of their synapses in the ganglia of the leech: a study using intracellular injection of horseradish peroxidase. Proc R Soc Lond [Biol] 194:481-499.

Nazif F, Byrne JH, Cleary LJ (1989) Intracellular injection of cAMP produces a long-term $(24 \mathrm{hr})$ increase in the number of varicosities in pleural sensory neurons of Aplysia. Soc Neurosci Abstr 15:1283.

Nguyen PV, Atwood HL (1990) Expression of long-term adaptation of synaptic transmission requires a critical period of protein synthesis. J Neurosci 10:1099-1109.

Pearce J, Govind CK, Shivers RR (1986) Intramembranous organization of lobster excitatory neuromuscular synapses. J Neurocytol 15 : 241-252.

Rheuben MB (1984) Quantitative comparison of the structural features of slow and fast neuromuscular junctions in Manduca. J Neurosci 5:1704-1716.

Robbins N, Fischbach GD (1971) Effect of chronic disuse of rat soleus neuromuscular junctions on presynaptic function. J Neurophysiol 34: 570-578.

Sasaki-Sherrington SE, Jacobs JR, Stevens JK (1984) Intracellular control of axial shape in non-uniform neurites: a serial electron microscopic analysis of organelles and microtubules in AI and AII retinal amacrine neurites. J Cell Biol 98:1279-1290.

Sirevaag AM, Greenough WT (1987) Differential rearing effects on rat visual cortex synapses. III. Neuronal and glial nuclei, boutons, dendrites, and capillaries. Brain Res 424:320-332.
Stewart WW (1981) Lucifer dyes-highly fluorescent dyes for biological tracing. Nature 292:17-21.

Tieman DG, Murphey RK, Schmidt JT, Tieman SB (1986) A computer-assisted video technique for preparing high resolution pictures and stereograms from thick specimens. J Neurosci Meth 17:231-245.

Tieman SB (1985) The anatomy of geniculocortical connections in monocularly deprived cats. Cell Mol Neurobiol 5:35-45.

Titmus MJ (1981) Ultrastructure of identified fast excitatory, slow excitatory and inhibitory neuromuscular junctions in the locust. $\mathbf{J}$ Neurocytol 10:363-385.

Turner AM, Greenough WT (1985) Differential rearing effects on rat visual cortex synapses. I. Synaptic and neuronal density and synapses per neurone. Brain Res 329:195-203.

Waerhaug O, Korneliussen H (1974) Morphological types of motor nerve terminals in rat hindlimb muscles, possibly innervating different muscle fiber types. Z Anat Entwickl Gesch 144:237-247.

Walrond JP, Reese TS (1985) Structure of axon terminals and active zones at synapses on lizard twitch and tonic muscle fibers. J Neurosci 5:662-672.

Watson AHD, Burrows M (1981) Input and output synapses on identified motor neurones of a locust revealed by the intracellular injection of horseradish peroxidase. Cell Tissue Res 215:325-332.

Wiersma CAG (1961) The neuromuscular system. In: The physiology of crustacean, Vol 2, Sense organs, integration and behavior (Waterman TH, ed), pp 191-240. New York: Academic.

Wiesel TN, Hubel DH (1965) Comparison of the effects of unilateral and bilateral eye closure on cortical unit responses in kittens. J Neurophysiol 28:1029-1040.

Wojtowicz JM, Atwood HL (1984) Presynaptic membrane potential and transmitter release at the crayfish neuromuscular junction. J Neurophysiol 52:99-113. 